\title{
Coconut Oil Reduces Visceral Adipocyte Size and Improves the Metabolic Profile of Rats Fed a High-Carbohydrate Diet
}

\author{
Valéria Schoffen Romão-Carrascoza ${ }^{1}$, Rosângela Fernandes Garcia ${ }^{1}$, Lorena Lima Gargaro ${ }^{2}$, Maria Montserrat Diaz \\ Pedrosa $^{1}$, Nilton de Almeida Brito ${ }^{1}$, Clairce Luzia Salgueiro-Pagadigorria ${ }^{1}$ and Márcia do Nascimento Brito ${ }^{1}$ \\ 1. Department of Physiological Sciences, State University of Maringá, Maringá 87020900, PR, Brazil \\ 2. Department of Medicine, State University of Maringá, Maringá 87020900, PR, Brazil
}

\begin{abstract}
This work aimed to evaluate the effects of the food supplementation with coconut oil (CO) on biometric and metabolic parameters in an animal model of obesity. Wistar rats fed a high-carbohydrate diet (HCD rats) develop metabolic disorders very similar to those found in human metabolic syndrome, including increased adiposity, insulin resistance (IR), non-alcoholic fatty liver disease (NAFLD) and dyslipidemia. Although HCD rats had normal fasting glycemia, they developed IR as revealed by Homa-IR index and, after glucose overload, exhibited higher peaks of insulinemia and glycemia. These alterations were accompanied by a higher formation of advanced glycated end products (AGEs). The supplementation with CO improved IR, reduced AGEs formation and reverted NAFLD. These effects could be due to CO action of reducing visceral adipocyte size and take place without undesirable collateral effects on lipid profile, placing $\mathrm{CO}$ as an adjuvant in the treatment of the metabolic syndrome.
\end{abstract}

Key words: Adipocyte hypertrophy, metabolic syndrome, insulin resistance, NAFLD, coconut oil.

\section{Introduction}

Metabolic syndrome (MSyn) is a multifactorial condition characterized by visceral obesity, hypertension, hyperglycemia, insulin resistance (IR) and dyslipidemia that can increase the risk of type 2 diabetes, cardiovascular diseases and non-alcoholic fatty liver disease (NAFLD) [1, 2].

The link between the individual MSyn components is not totally known, but the frequent combination of these metabolic abnormalities suggests that they are indeed interrelated, and that just a few factors may underlie such combination.

Over 4 decades ago, adipocyte size was shown to vary inversely with adipocyte insulin sensitivity [3]. Studies have shown functional differences between large and small adipocytes [4-6]. In general, the hypertrophy of visceral, in comparison with

Corresponding author: Rosângela Fernandes Garcia, Ph.D., professor, research fields: liver metabolism and nutrition. subcutaneous, adipocytes leads to more detrimental metabolic effects [7,8], first because the enlarged visceral adipocytes exhibit more remarkable physiological dysfunctions $[9,10]$ and second because of their close proximity to hepatic and visceral immune cells [11]. For instance, enlarged visceral adipocytes secrete large amounts of TNF- $\alpha$, which induces IR in both adipocytes and myocytes [12]. Thus, the enlarged visceral adipocytes display increased lipolysis, releasing fatty acids (FA) directly into the portal vein, overloading the liver and leading to liver fat accumulation [13]. In fact, IR has been considered the "first-level" contributing event for the pathogenesis of NAFLD and other metabolic and cardiovascular complications of obesity, the so-called IR-syndromes [14, 15].

It is a reasonable thought that the reduction of visceral fat depots should improve life expectancies. This is not always possible simply by changing lifestyle or eating habits. One of the alternative 
strategies has been to replace some of the conventional dietary long-chain triglyceride-rich (LCT, > 12 carbons FA) by medium-chain triglyceride-rich (MCT, 6-12 carbons) oil [16]. Lipids varying in FA chain lengths are metabolized differently. MCTs are absorbed directly into the portal circulation and transported to the liver for rapid oxidation [16, 17]. LCTs, on the other hand, are transported via chylomicrons into the lymphatic system, allowing for extensive uptake into adipose tissue. Therefore, the hypothesis has been put forward that the rapid metabolism of MCTs may increase energy expenditure and decrease their storage in adipose tissue $[18,19]$. All these results are suggestive that MCT could potentially prevent or control obesity in humans.

In this context, the intake of coconut oil (Cocos nucifera) has increased over the years. Cold-pressed coconut oil (CO) is composed of about 93\% medium-chain saturated FA, predominantly lauric and myristic acids. Studies aimed at investigating the effects of $\mathrm{CO}$ and MCT oil in body weight (BW) have demonstrated that it was effective in reducing central obesity without undesirable effects on plasma lipid profile [20-22]. However, the effects of $\mathrm{CO}$ on the size of adipocytes - an indirect indicator of IR - were not assessed in these studies.

Previous studies have reported that rats fed with high-carbohydrate diet (HCD) develop metabolic, cardiovascular and hepatic complications [23, 24] that are similar to human MSyn [25]. In this way, the purpose of this work was to evaluate the effects of $\mathrm{CO}$ on an animal model of obesity induced by HCD. The parameters evaluated included BW gain, adiposity index, adipocyte diameter, liver lipid contents, plasma lipid profile, glycemia, insulinemia and the formation of advanced glycated end-products (AGEs).

\section{Material and Methods}

\subsection{Materials}

Kits from Gold Analisa ${ }^{\circledR}$ (Belo Horizonte, Brazil) were used to measure blood levels of lipids, glucose and fructosamine. Sodium heparin was obtained from Roche (São Paulo, Brazil). The other reagents were from Merck (Darmstadt, FRG), Carlo Erba (São Paulo, Brazil) and Reagen (Rio de Janeiro, Brazil). Plasma insulin levels were measured by radioimmunoassay (Wizard2 Automatic Gamma Counter ${ }^{\circledR}$, TM-2470, PerkinElmer, Shelton-CT, EUA). A commercially available extra-virgin coconut oil was used and its composition is presented in Table 1 .

\subsection{Animals, Diets and Treatment}

This study was approved by the Ethics Committee for the Use of Animals of the State University of Maringá (Certificate No. 018/2014).

Male Wistar rats $(n=35)$ aging 21 days (weaned) were kept under controlled temperature $\left(23{ }^{\circ} \mathrm{C}\right)$ and photoperiod (12 h light/12 h dark) in polypropylene cages. Eleven rats were fed with a standard rodent chow (Nuvilab CR $1^{\circledR}$, Nuvital, Brazil) (CON rats, $\left.n=11\right)$

Table 1 Fatty acid composition of coconut oil (CO).

\begin{tabular}{ll}
\hline Fatty acid & $\% / 100 \mathrm{~g} \mathrm{CO}$ \\
\hline Caproic acid C6:0 & 0.38 \\
Caprylic acid C8:0 & 5.56 \\
Capric acid C10:0 & 4.99 \\
Lauric acid C12:0 & 45.78 \\
Myristic acid C14:0 & 18.56 \\
Palmitic acid C16:0 & 8.85 \\
Stearic acid C18:0 & 3.39 \\
Oleic acid C18:1 & 5.65 \\
Linoleic acid C18:2 & 0.94 \\
\hline
\end{tabular}


and twenty-four rats were fed with high-carbohydrate diet (HCD rats). The HCD was composed of 33\% standard chow, 33\% condensed milk (Nestle ${ }^{\circledR}$, Brazil), $7 \%$ crystalized sugar (União ${ }^{\circledR}$, Brazil) and $8.6 \%$ water. The nutritional values of the standard and $\mathrm{HC}$ diets were, respectively: 402 and $428 \mathrm{kcal} / 100 \mathrm{~g} ; 57.5$ and $68 \%$ carbohydrate; 30 and $16 \%$ protein; 12.5 and $16 \%$ fat [23]. Diets were offered in pellets and ad libitum.

After 10 weeks, twelve HCD rats were treated with extra-virgin coconut oil (HCD + CO rats) for 4 weeks, at the dose of $6 \mathrm{mg} / 100 \mathrm{~g}$ body weight (BW) by esophageal gavage (final volume of $0.1 \mathrm{~mL} / 100 \mathrm{~g} \mathrm{BW}$ ) divided into two administrations, which were done at 10:00 AM and 5:00 PM. The other twelve untreated HCD rats and the CON rats were given the same volume of saline. The dose of $\mathrm{CO}$ was chosen based on Assunção et al. [20].

The entire experimental period lasted 14 weeks, during which the animals were recorded for their BW once a week and food ingestion every two days to calculate total food intake. Weight gain was calculated as the difference between the final weight and the initial weight.

At the age of 120 days, the animals were used for the experiments described below.

\subsection{Intravenous Glucose Tolerance Test (ivGTT)}

To perform these tests, a polyethylene cannula was inserted in the right jugular vein [26] under anesthesia (thionembutal $40 \mathrm{mg} / \mathrm{kg}$ BW after lidocaine $5 \mathrm{mg} / \mathrm{kg}$ $\mathrm{BW})$ on the day before the experiments. The cannula was used for glucose infusion as a "bolus" (1 g glucose $/ \mathrm{kg} \mathrm{BW}$ ) and collection of blood samples at the times $0,5,15,30,45$ and $60 \mathrm{~min}$, time $0 \mathrm{~min}$ being immediately before glucose infusion. The ivGTT was performed at 8:00 AM after an overnight fasting. The blood samples collected were transferred to heparin-coated tubes and centrifuged for glucose determination. Plasma samples were kept at $-20{ }^{\circ} \mathrm{C}$ for insulin measurements. The fasting insulinemia and glycemia were used to calculate the IR, expressed in terms of the homeostasis model assessment of IR (HOMA-IR Index) [27]. Plasma glucose was expressed as $\mathrm{mg} / \mathrm{dL}$ and insulinemia as $\mathrm{ng} / \mathrm{mL}$.

\subsection{Removal of Tissues and Collection of Blood}

After the glucose tolerance test, euthanasia was carried out with a lethal dose of thionembutal (100 $\mathrm{mg} / \mathrm{kg}$ BW, i.p.). Blood samples were collected by cardiac puncture and the serum was used to measure fructosamine, total cholesterol (TC), high-density lipoprotein (HDL) and triglycerides (TG). Samples of liver were removed, clamped in liquid nitrogen and stored at $-80{ }^{\circ} \mathrm{C}$ for further determination of lipid content. In addition, fat depots (epididymal, mesenteric, retroperitoneal and inguinal) were removed and weighed. The adiposity index was defined as the sum of fat weight/100 g BW [28]. The retroperitoneal adipose tissue was used to determine adipocyte size. The respective protocols are described below.

\subsection{Serum Biochemical Analyses}

Total cholesterol, HDL and TG were analyzed in serum by standard methods using assay kits (Gold Analisa $^{\circledR}$ ). Very low-density lipoprotein (VLDL) levels were calculated using the Friedewald's equation [29] and low-density lipoprotein (LDL) levels were determined by subtracting HDL and VLDL from TC. The values were expressed as $\mathrm{mg} / \mathrm{dL}$. Fructosamine was used as a marker of long-term glycemic control and formation of AGEs. The levels of fructosamine were evaluated using commercial kits (Gold Analisa ${ }^{\circledR}$, Brazil) and expressed as mmol/L.

\subsection{Determination of Hepatic Lipid Content}

The liver total lipid content was determined using the gravimetric method [30], which is based on the extraction of lipids from homogenized liver samples (approximately $1.0 \mathrm{~g}$ ) in a chloroform-methanol mixture (2:1). Lipids were resuspended in $2 \%$ Triton, followed by agitation and heating to $55{ }^{\circ} \mathrm{C}$. TC and 
TG contents were measured using commercial kits (Gold Analisa ${ }^{\circledR}$, Brazil). The results were expressed as $\mathrm{g} / \mathrm{g}$ of liver wet weight.

\subsection{Adipocyte Isolation and Adipocyte Cell Size} Determination

Adipocytes were isolated using a modified version of the method described by Rodbell [31]. Briefly, the retroperitoneal adipose tissue (approximately $1.0 \mathrm{~g}$ ) was cut into fine pieces and put into $4.0 \mathrm{~mL}$ digestive buffer $\mathrm{pH} 7.5$ containing $1.0 \mathrm{~g} \%$ glucose-free DMEM (Dulbecco's Modified Eagle Medium Base), $1 \mathrm{mM}$ sodium pyruvate, $4.2 \mathrm{mM}$ sodium bicarbonate, $25 \mathrm{mM}$ HEPES, $4.0 \mathrm{~g} \%$ bovine serum albumin, $1 \mathrm{mg} / \mathrm{mL}$ type II collagenase, $1 \mathrm{mg} \%$ phenol red. The samples were incubated in an orbital agitation water bath at $37^{\circ} \mathrm{C}$ for $60 \mathrm{~min}$. The cell suspension was filtered through a double layer of nylon cloth and then washed three times by flotation in a medium containing: $0.81 \mathrm{mM}$ magnesium sulfate, $5.4 \mathrm{mM}$ potassium chloride, 0.11 M sodium chloride, $1.2 \mathrm{mM}$ sodium phosphate monobasic, $1.4 \mathrm{mM}$ calcium chloride, $25 \mathrm{mM}$ HEPES, $1 \mathrm{mM}$ sodium pyruvate, $1 \mathrm{mg} \%$ phenol red and $1 \mathrm{~g} \%$ bovine serum albumin, $\mathrm{pH}$ 7.5.

The washed cell suspension was placed on a glass slide and the images of the adipocytes were captured at $40 \times$ original magnification with a high-resolution digital camera (Pro-Media Series, Cibertecnics ${ }^{\circledR}$ ) coupled to an optical microscope Olympus BX $40^{\circledR}$, Japan) with 50- $\mu \mathrm{m}$ scale bar. Adipocyte diameters (50 cells per animal) were measured using a computerized image analysis system (Image Pro-Plus ${ }^{\circledR}$, Media Cybernetics, USA).

\subsection{Statistical Analyses}

The results were expressed as mean \pm standard error (SE). Prism 5.0 ${ }^{\circledR}$ (GraphPad, USA) was used to calculate the area under curve (AUC) and perform the statistical analyses (One-way ANOVA followed by the Tukey's test). The level of significance was set at $5 \%$.

\section{Results}

\subsection{Progression of $B W$}

Fig. 1 shows the time course of BW gain of the three animal groups, from weaning (21 days old, week zero) until the end of the experimental period (week 14). At 21 days, the $\mathrm{BW}$ of the animals of the three groups was similar $(\mathrm{CON}=39.4 \pm 1.0 \mathrm{~g} ; \mathrm{HCD}=39.8 \pm 1.1 \mathrm{~g}$; $\mathrm{HCD}+\mathrm{CO}=39.0 \pm 1.0 \mathrm{~g}$ ). Even after the animals started to receive different diets this tendency did not

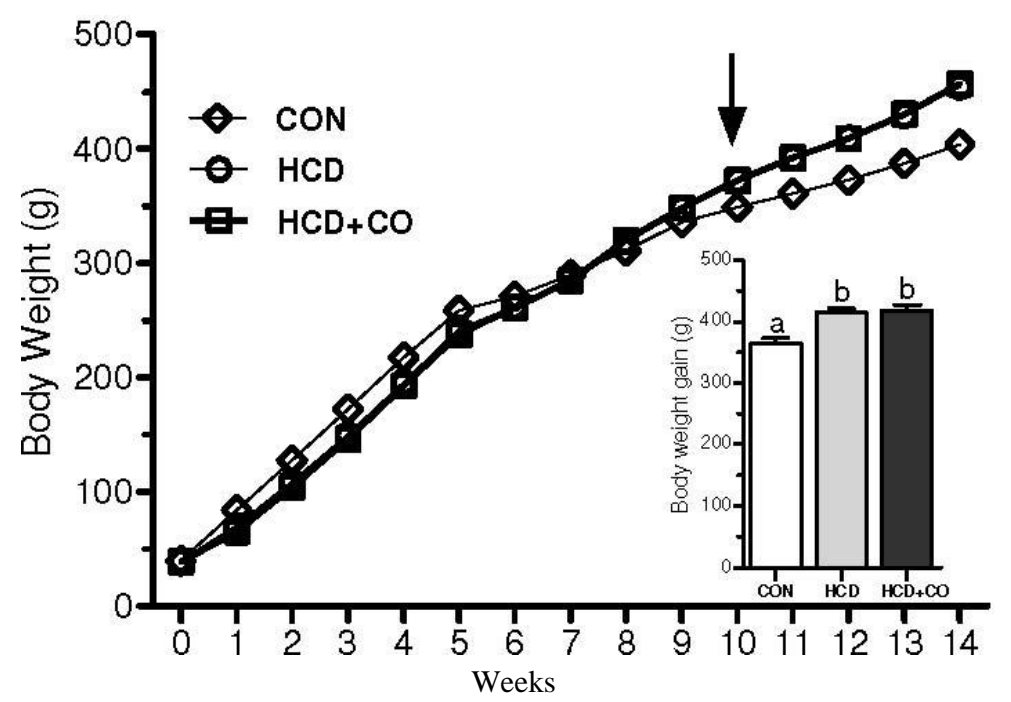

Fig. 1 Body weight of CON, HCD and HCD + CO rats from weaning (Week 0) until the end of the experimental period (Week 14). The arrow shows the beginning of the supplementation with $\mathrm{CO}$ (Week 10, $6 \mathrm{mg} / 100 \mathrm{~g} \mathrm{BW}$ ). The columns are the BW gain and are expressed as the mean \pm SE $(n=11-12$ /group $)$. Different letters represent statistical difference $(p<0.05)$. 
change until Week 10. Coincidentally, this was the onset of the supplementation with CO. However, all HCD rats exhibited greater weight, regardless of supplementation with $\mathrm{CO}$ or not. At the end of Week 14, HCD and HCD + CO rats were heavier than CON rats by about $13 \%$.

The animals were evaluated for adipose tissue mass and adiposity index. As shown in Fig. 2, HCD and $\mathrm{HCD}+\mathrm{CO}$ rats exhibited significant and similar increases in their epididymal (+49\%) and retroperitoneal $(+64 \%)$ fat depots. Although no alterations were seen in the inguinal or mesenteric fats (> 0.05 compared with $\mathrm{CON}$ rats), there was a remarkable increase in the adiposity index in these groups $(+33 \%)$ compared with CON rats.

The changes in BW and adiposity index were correlated with changes in food intake, since all the animals ingested similar amounts of chow $(p>0.05)$ along the entire experimental period (CON rats $2,274.80 \pm 38.9 \mathrm{~g}$; HCD rats $2,236.10 \pm 25.9 \mathrm{~g}$; HCD $+\mathrm{CO}$ rats $2,234.9 \pm 32.9 \mathrm{~g}$ ).

\subsection{Determination of Adipocyte Diameter}

The results of retroperitoneal adipocyte diameters are presented in Fig. 3. The HCD rats had larger adipocytes compared with CON rats; the supplementation with CO reversed this hypertrophy.

\subsection{Biochemical Blood Analysis}

Table 2 shows the blood metabolic profile of the three groups after overnight fasting at the end of the 14 weeks. All animals had normal and similar fasting glycemia $(p>0.05)$, but HCD and HCD-CO rats had much higher insulin levels than CON rats. The supplementation with $\mathrm{CO}$, however, significantly reduced this level so that insulin level in $\mathrm{HCD}+\mathrm{CO}$ rats was intermediary between $\mathrm{HCD}$ and $\mathrm{CON}$ rats but different from both. The insulin sensitivity, as assessed by Homa-IR index, matched the insulin level of each group - it was much greater in HCD rats, intermediary in $\mathrm{HCD}+\mathrm{CO}$ rats and lower in $\mathrm{CON}$ rats.

As for the lipid profile, although TC, HDL and LDL did not differ between the groups, VLDL-cholesterol and TG levels were significantly and similarly increased in both $\mathrm{HCD}$ and $\mathrm{HCD}+\mathrm{CO}$ rats, by approximately $26 \%$, compared with $\mathrm{CON}$ rats.

\subsection{Glucose Tolerance Test}

The values of glycemia and insulinemia obtained

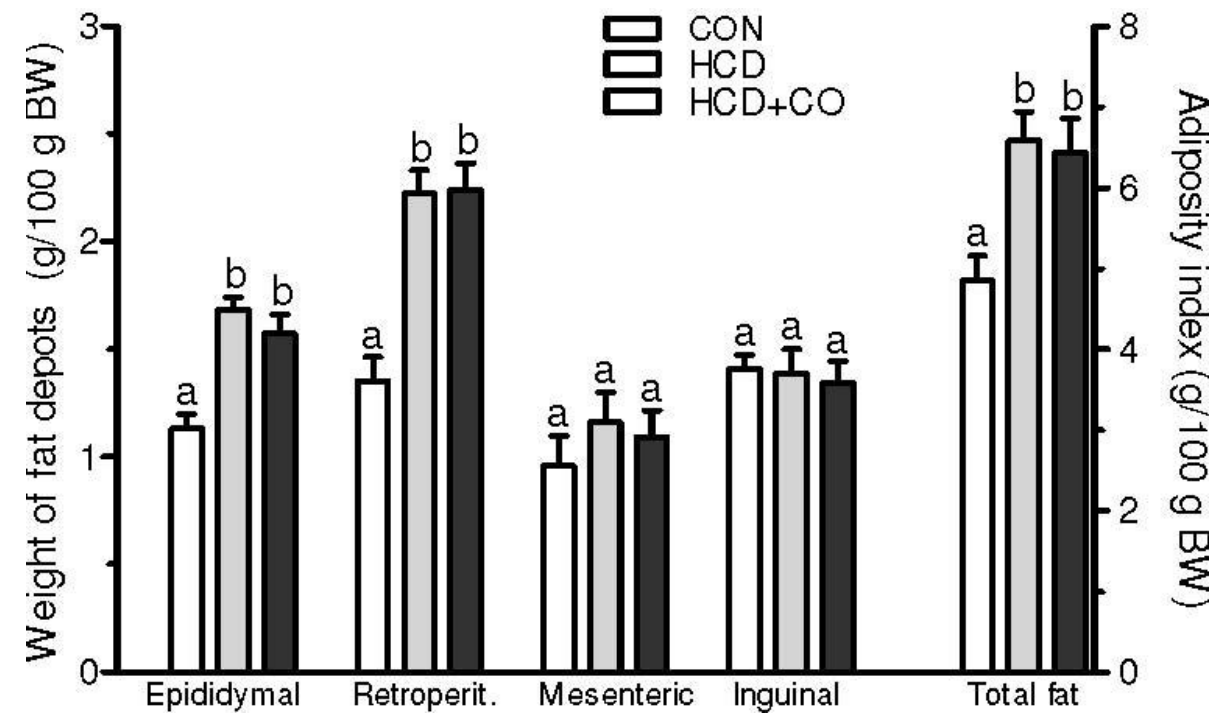

Fig. 2 Adipose tissue weight and adiposity index of CON, HCD and HCD + CO rats. The results are expressed as mean \pm SE $(n=11-12 /$ group $)$. Different letters represent statistical difference $(p<0.05)$. 

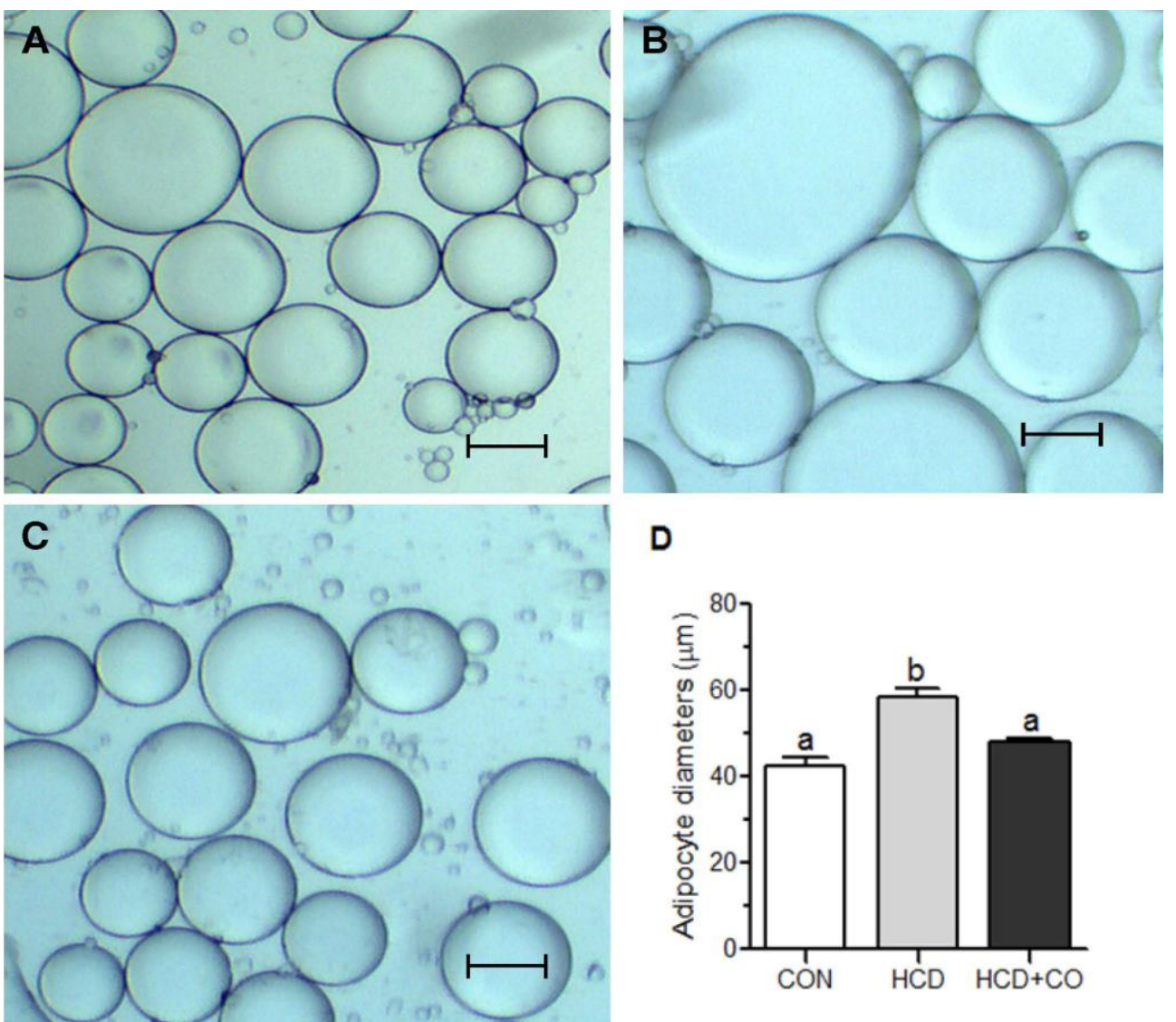

D

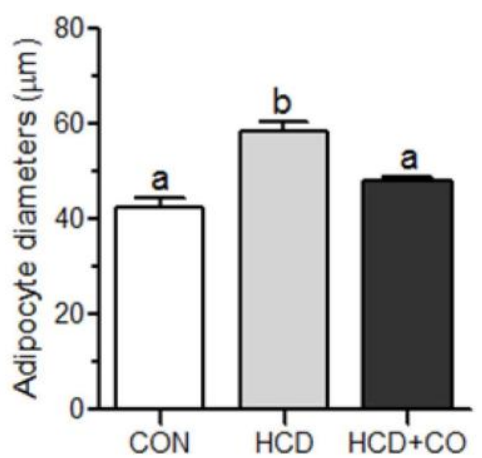

Fig. 3 Isolated retroperitoneal adipocytes of CON (A), HCD (B) and HCD + CO (C) rats and adipocyte diameters (D). The results are expressed as mean \pm SE $(n=8$ /group). Different letters represent statistical difference $(p<0.05)$.

Table 2 Biochemical blood parameters of CON, HCD and HCD + CO rats.

\begin{tabular}{llll}
\hline Parameters & CON & HCD & HCD+CO \\
\hline Glycemia $(\mathrm{mg} / \mathrm{dL})$ & $79.89 \pm 1.70^{\mathrm{a}}$ & $80.42 \pm 2.77^{\mathrm{a}}$ & $82.90 \pm 3.53^{\mathrm{a}}$ \\
Insulinemia $(\mathrm{ng} / \mathrm{mL})$ & $0.051 \pm 0.26^{\mathrm{a}}$ & $0.209 \pm 0.06^{\mathrm{b}}$ & $0.159 \pm 0.04^{\mathrm{c}}$ \\
Homa-IR index & $0.165 \pm 0.03^{\mathrm{a}}$ & $0.671 \pm 0.14^{\mathrm{b}}$ & $0.311 \pm 0.05^{\mathrm{c}}$ \\
TG $(\mathrm{mg} / \mathrm{gL})$ & $89.14 \pm 7.26^{\mathrm{a}}$ & $118.96 \pm 9.07^{\mathrm{b}}$ & $119.71 \pm 7.35^{\mathrm{b}}$ \\
TC $(\mathrm{mg} / \mathrm{dL})$ & $76.48 \pm 3.23^{\mathrm{a}}$ & $85.66 \pm 1.49^{\mathrm{a}}$ & $86.33 \pm 1.86^{\mathrm{a}}$ \\
HDL $(\mathrm{mg} / \mathrm{dL})$ & $32.86 \pm 2.27^{\mathrm{a}}$ & $34.21 \pm 1.01^{\mathrm{a}}$ & $35.00 \pm 1.66^{\mathrm{a}}$ \\
LDL $(\mathrm{mg} / \mathrm{dL})$ & $25.79 \pm 2.83^{\mathrm{a}}$ & $27.65 \pm 1.94^{\mathrm{a}}$ & $27.38 \pm 1.94^{\mathrm{a}}$ \\
VLDL $(\mathrm{mg} / \mathrm{dL})$ & $17.83 \pm 1.45^{\mathrm{a}}$ & $23.79 \pm 1.81^{\mathrm{b}}$ & $23.94 \pm 1.47^{\mathrm{b}}$ \\
\hline
\end{tabular}

The results are expressed as mean \pm SE $(n=10$-12 /group). Different letters represent statistical difference $(p<0.05)$.

during the ivGTT are given in Figs. 4A and 4B, respectively. The histograms are AUCs of both measures. HCD rats had higher glycemic and insulinemic indices than $\mathrm{CON}$ rats. The supplementation with $\mathrm{CO}$ could restore these values, as shown by the AUC values.

\subsection{Liver Total Lipid Content}

Fig. 5 shows the results of liver total lipid content.
The livers of CON rats had normal lipid content of about 5\% [32]. However, in HCD rats, it increased $21 \%$, characterizing extensive NAFLD. The supplementation with $\mathrm{CO}$ totally reversed this condition.

\subsection{Determination of Fructosamine}

Plasma fructosamine concentrations (Fig. 6) were used as an index of long-term glycemic control and 

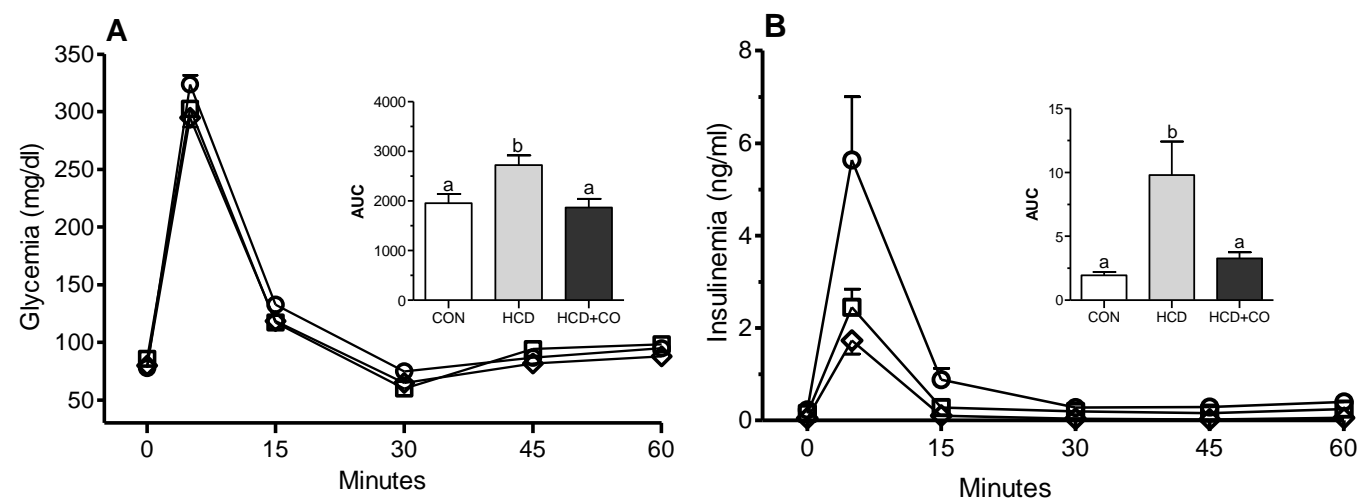

Fig. 4 Glycemic (A) and insulinemic (B) curves during intravenous glucose tolerance test of CON ( $\diamond)$, HCD ( $(\circ)$ and $\mathrm{HCD}+\mathrm{CO}(\square)$ rats. Histograms are the AUCs of the respective curves. Results are expressed as mean $\pm \mathrm{SE}(n=8-10 / \mathrm{group})$. Different letters represent statistical difference $(p<0.05)$.

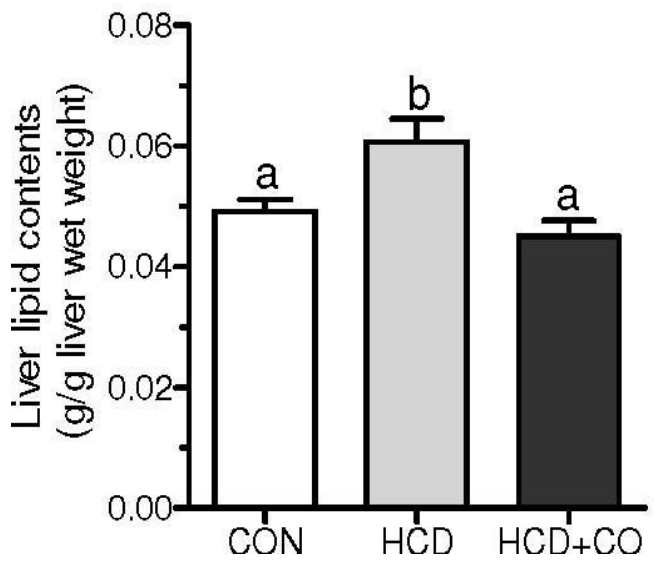

Fig. 5 Liver total lipid content of CON, HCD and HCD + $\mathrm{CO}$ rats. The results are expressed as means $\pm \mathrm{SE}(n=$ 10/group). Different letters represent statistical difference $(p<0.05)$.

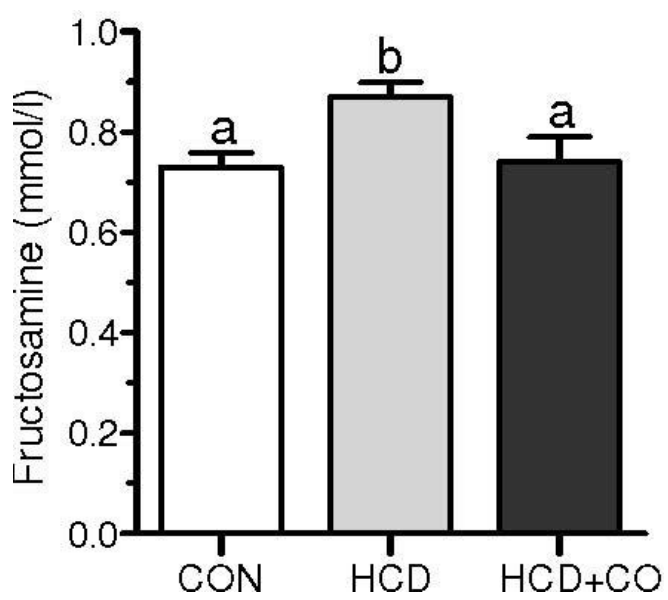

Fig. 6 Plasma fructosamine of CON, HCD and HCD + CO rats. Results are expressed as mean $\pm \mathrm{SE}(n=9-10$ /group).
Different letters represent statistical difference $(p<0.05)$.

AGE formation. The fructosamine levels were increased in $\mathrm{HCD}$ rats compared with $\mathrm{CON}$ and the supplementation with CO normalized this parameter.

\section{Discussion}

The rats fed with HCD developed metabolic disorders very similar to those of human MSyn, including increased adiposity, IR, NAFLD and dyslipidemia, as previously described [23]. Although HCD rats had normal fasting glycemia, they had IR as revealed by Homa-IR index; moreover, after a glucose overload, they had higher peaks of insulinemia and glycemia. These alterations were accompanied by a higher AGE formation, as assessed by measurements of fructosamine levels. As serum proteins have a faster turnover than other proteins they allow the detection of rapid fluctuations in plasma glucose levels [33].

The supplementation with $\mathrm{CO}$ ameliorated IR, as demonstrated by Homa-IR index and the lower peaks of insulinemia and glycemia during the glucose challenge. NAFLD, assessed by the liver lipid content, was also reversed by $\mathrm{CO}$. We can assume that the primary effect of $\mathrm{CO}$ would be reducing the size of visceral (retroperitoneal) adipocytes, since it did not change adipose tissue weight or adiposity index. The logic of this reasoning is supported by O'Connell et al. 
[8], who compared healthy and unhealthy severely obese men and observed that omental, but not subcutaneous, adipocyte sizes are correlated with metabolic disturbances, and that the individual's adipocyte size is more important than his body weight. These same observations were made by comparing lean and obese humans [10, 34]. The decreased adipocyte size not accompanied by decreased retroperitoneal weight can be ascribed to a persistent fibrosis of the extracellular matrix, which is enhanced by body weight gain [35].

Enlarged visceral adipocytes exhibit the most pronounced diameter-related alterations, including high levels of tumor necrosis factor (TNF- $\alpha$ ) [4] and low adiponectin release [36], which were shown to be related with lower adipocyte responsiveness to insulin [12], increased lipolysis [13] and lower glucose uptake [5]. In addition to inducing IR TNF- $\alpha$, together with other cytokines, such as interleukin (IL) $1 \beta$, are pro-inflammatory [11]. Recent studies performed with obese, postmenopausal women have revealed that, by replacing common vegetal oil by $\mathrm{CO}$, the plasma levels of TNF- $\alpha$ and IL-1 $\beta$ decreased, as well as the inflammation [37]. It has also been demonstrated that MCTs inhibit the production of inflammatory cytokines [38], once again supporting our hypothesis.

The increased lipolysis by the insulin resistant visceral adipocytes overloads the liver with FA [13]. Additionally, insulin robustly stimulates liver de novo lipogenesis, decreases FA oxidation [38] and promotes autophagic degradation of apolipoprotein B100 (apoB100), thus limiting the release of VLDL from the liver [39]. Together, these events trigger NAFLD, as observed here for HCD rats. Our results also demonstrated that the improvement of IR by $\mathrm{CO}$ was accompanied by a reversal of NAFLD in HCD + $\mathrm{CO}$ rats.

Beyond hyperinsulinemia, another factor in HCD rats that could impair the lipid disposal pathways is the inhibition of the enzyme carnitine palmitoyl transferase I (CPT-I) by malonyl-CoA, in this condition of dietary carbohydrate abundance. This first limiting enzyme for the oxidation of long chain fatty acids (LCFA) is located at the mitochondrial outer membrane, where it controls the conversion of acyl-CoA into acyl-carnitine, its access to the mitochondrial matrix and, therefore, the rate of mitochondrial LCFA oxidation. CPT-I is physiologically inhibited by malonyl-CoA, which is formed from acetyl-CoA in the first (limiting) step of the de novo FA synthesis [40]. Thus, high rates of fatty acid synthesis result in low rates of fatty acid oxidation, and vice versa.

As medium chain fatty acids (MCFA) enter mitochondria independently of CPT-I, excess carbohydrates (which are converted to malonyl-CoA) may not inhibit their oxidation [40]. In this way, it is expected that the supplementation with $\mathrm{CO}$ during HCD would bring about a novel situation to the liver: $\beta$-oxidation (of MCFA) as well as the production of malonyl-CoA and subsequent de novo FA synthesis (from carbohydrates) should be accelerated. As the oxidation of MCFA has been associated with increased oxygen consumption and energy expenditure compared to LCFA [18], the reduction of fat liver deposits, as observed in HCD + CO rats, was not surprising.

Some of the lipids synthesized within the hepatocytes are released into the bloodstream as VLDL. The fasting VLDL levels were increased in HCD rats, probably as a consequence of the physiological impairment of hepatic insulin regulation of apoB100 as a result of liver fat accumulation [39]. Insulin stimulation of de novo lipogenesis occurs independent of its effects on apoB100. Thus, increased release of VLDL and hypertriglyceridemia are common features in the setting of hyperinsulinemia and IR [41].

In this way, in HCD rats, the increase of fasting VLDL and TG levels should reflect VLDL hyper-secretion rather than reduced clearance of TG by adipose tissue lipoprotein lipase (LPL). In fact, this 
rate-limiting enzyme, is activated by insulin, thus promoting fat storage [42].

In $\mathrm{HCD}+\mathrm{CO}$ rats, the VLDL and TG levels were also similarly increased, but we believe that the mechanisms involved in this were quite distinct. Normally, in the liver, LCFA is more efficiently incorporated in VLDL than MCFA. However, in long-term experiments, the situation could be altered in such a way that hypertriglyceridemia would appear as a direct consequence of MCT intake, as has been demonstrated in animal studies [43] and human surveys [44]. In addition, in $\mathrm{HCD}+\mathrm{CO}$ rats a reduction in LPL activity could contribute to the increase in VLDL and TG, as already described for Zucker rat adipose tissue during long-term MCT feeding [45].

Despite these undesirable effects of $\mathrm{CO}$ observed in the present study in rats fed with HCD, epidemiologic studies of African and South Pacific populations whose diets contain coconuts have revealed no association between coconut oil ingestion and obesity or dyslipidemia [46, 47]. Other studies investigating the effect of coconut oil in humans obtained conflicting results concerning lipid profile and body weight $[20,21,48]$.

Finally, our results demonstrated that the endogenous formation of AGE (as judged by plasma fructosamine), was increased in HCD rats. The importance of the endogenous formation of AGEs began to be recognized in the 1970's when glycated hemoglobin $(\mathrm{HbA1c})$ was found to be associated with diabetes hyperglycemia [49]. AGEs act on many receptors, including the receptor for advanced glycation end products (RAGE) [50]. RAGE activation induces ROS generation and inflammation via activation of NADH oxidase and release of TNF- $\alpha$ $[51,52]$. Elevated TNF- $\alpha$ further increases ROS formation, which triggers the mitochondrial pathway of cell death [53]. The higher ROS formation, in turn, leads to a higher expression of RAGE. Altogether, these events create vicious cycles of oxidative and inflammatory damage. There is now strong evidence that the accumulation of AGEs results in changes of extracellular matrix structure and function, and they have been implicated in the pathogenesis of renal, neurological, retinal and vascular diabetic complications [54]. In this way, the finding that $\mathrm{CO}$ was able to prevent the elevations of fructosamine, a marker of AGE formation, was very encouraging.

\section{Conclusions}

In conclusion, the supplementation with $\mathrm{CO}$ improved several effects caused by HCD, including a decrease of visceral adipocyte size, improvement of IR, reduced AGE formation and reversal of NAFLD, without undesirable effects on the lipid profile. These results suggest that $\mathrm{CO}$ may be an important adjuvant in the treatment of the metabolic syndrome.

\section{Conflict of Interests}

All authors indicated no potential conflict of interests relevant to this paper.

\section{Acknowledgments}

We are thankful to Dr. Emy L. Ishii Iwamoto, Dr. Maria Raquel M. Natali and Dr. Paulo C. F. Mathias for kindly granting access to their technical support and laboratories.

\section{References}

[1] Kaplan, N. M. 1989. "The Deadly Quartet. Upper-Body Obesity, Glucose Intolerance, Hypertriglyceridemia, and Hypertension." Arch Intern Med 149: 1514-20.

[2] Isomaa, B., Almgren, P., Tuomi, T., Forsen, B., Lahti, K., Nissen, M., Taskinen, M. R., and Groop, L. 2001. "Cardiovascular Morbidity and Mortality Associated with the Metabolic Syndrome.” Diabetes Care 24: 683-9.

[3] Salans, L. B., Knittlem J. L., and Hirsch, J. 1968. "The Role of Adipose Cell Size and Adipose Tissue Insulin Sensitivity in the Carbohydrate Intolerance of Human Obesity." J Clin Invest 47: 153-65.

[4] Winkler, G., Kiss, S., Keszthelyi, L., Sapi, Z., Ory, I., Salamon, F., Kovacs, M., Vargha, P., Szekeres, O., Speer, G., Karadi, I., Sikter, M., Kaszas, E., Dworak, O.,Gero, G., and Cseh, K. 2003. "Expression of Tumor Necrosis 

Rats Fed a High-Carbohydrate Diet

Factor (TNF)-Alpha Protein in the Subcutaneous and Visceral Adipose Tissue in Correlation with Adipocyte Cell Volume, Serum TNF-Alpha, Soluble Serum TNFreceptor-2 Concentrations and C-Peptide Level." Eur J Endocrinol 149: 129-35.

[5] Franck, N., Stenkula, K. G., Ost, A., Lindstrom, T., Stralfors, P., and Nystrom, F. H. 2007. "Insulin-Induced GLUT4 Translocation to the Plasma Membrane Is Blunted in Large Compared with Small Primary Fat Cells Isolated from the Same Individual." Diabetologia 50: 1716-22.

[6] Skurk, T., Alberti-Huber, C., Herder, C., and Hauner, H. 2007. "Relationship between Adipocyte Size and Adipokine Expression and Secretion." J Clin Endocrinol Metab 92: 1023-33.

[7] Liu, K. H., Chan, Y. L., Chan, W. B., Chan, J. C., and Chu, C. W. 2006. "Mesenteric Fat Thickness Is an Independent Determinant of Metabolic Syndrome and Identifies Subjects with Increased Carotid Intima-Media Thickness." Diabetes Care 29: 379-84.

[8] O'Connell, J., Lynch, L., Cawood, T. J., Kwasnik, A., Nolan, N., Geoghegan, J., McCormick, A., O'Farrelly, C., and O'Shea D. 2010. "The Relationship of Omental and Subcutaneous Adipocyte Size to Metabolic Disease in Severe Obesity." PLoS One 5: e9997.

[9] Drolet, R., Belanger, C., Fortier, M., Huot, C., Mailloux, J., Legare, D., and Tchernof, A. 2009. "Fat Depot-Specific Impact of Visceral Obesity on Adipocyte Adiponectin Release in Women." Obesity (Silver Spring) 17: 424-30.

[10] Yang, Y. K., Chen, M., Clements, R. H., Abrams, G. A., Aprahamian, C. J., and Harmon, C. M. 2008. "Human Mesenteric Adipose Tissue Plays Unique Role versus Subcutaneous and Omental Fat in Obesity Related Diabetes." Cell Physiol Biochem 22: 531-8.

[11] Wajchenberg, B. L. 2000. "Subcutaneous and Visceral Adipose Tissue: Their Relation to the Metabolic Syndrome." Endocr Rev 21: 697-738.

[12] Diehl, A. M. 2004. "Tumor Necrosis Factor and Its Potential Role in Insulin Resistance and Nonalcoholic Fatty Liver Disease." Clin Liver Dis 8: 619-38.

[13] Petta, S., Gastaldelli, A., Rebelos, E., Bugianesi, E., Messa, P., Mieli, L. 2016. "Pathophysiology of Non-alcoholic Fatty Liver Disease.” Int J Mol Sci 17 (12): E2082. doi:10.3390/ijms17122082.

[14] Wellen, K. E., and Hotamisligil, G. S. 2005. "Inflammation, Stress, and Diabetes." J Clin Invest. 15: 1111-9.

[15] Grattagliano, I., Palmieri, V. O., Portincasa, P., Moschetta, A., and Palasciano, G. 2008. "Oxidative Stress-Induced Risk Factors as Sociated with the Metabolic Syndrome: A Unifying Hypothesis." J Nutr
Biochem 19: 491-504.

[16] St-Onge, M. P., and Jones, P. J. 2002. "Physiological Effects of Medium-Chain Triglycerides: Potential Agents in the Prevention of Obesity." J Nutr 132: 329-32.

[17] Sung, M. H., Liao, F. H., and Chien, Y. W. 2018. "Medium Chain Triglycerides Lower Blood Lipids and Body Weight in Streptozotocin-Induced Type 2 Diabetes Rats.” Nutrientes 26: 10. doi: 10.3390/nu10080963.

[18] St-Onge, M. P., and Jones, P. J. 2003. "Greater Rise in Fat Oxidation with Medium-Chain Triglyceride Consumption Relative to Long-Chain Triglyceride Is Associated with Lower Initial Body Weight and Greater Loss of Subcutaneous Adipose Tissue." Int J Obes Relat Metab Disord 27 (12): 1565-71.

[19] St-Onge, M., Ross, R., Parsons, W. D., and Jones, P. J. 2003. "Medium-Chain Triglycerides Increase Energy Expenditure and Decrease Adiposity in Overweight Men." Obes Res 11: 395-402. doi:10.1038/oby.2003. 53.

[20] Assunção, M. L., Ferreira, H. S., Santos, A. F., Cabral Jr, C. R., and Florencio, T. M. 2009. "Effects of Dietary Coconut Oil on the Biochemical and Anthropometric Profiles of Women Presenting Abdominal Obesity." Lipids 44: 593-601.

[21] Liau, K. M., Lee, Y. Y., Chen, C. K., amd Rasool, A. H. 2011. "An Open-Label Pilot Study to Assess the Efficacy and Safety of Virgin Coconut Oil in Reducing Visceral Adiposity." ISRN Pharmacol 2011: 949686. doi: 10.5402/2011/949686

[22] St-Onge, M. P., Bosarge, A., Goree, L. L., and Darnell, B. 2008. "Medium Chain Triglyceride Oil Consumption as Part of a Weight Loss Diet Does Not Lead to an Adverse Metabolic Profile when Compared to Olive Oil." J Am Coll Nutr 27: 547-52.

[23] Crepaldi, L. D., Mariano, I. R., Trondoli, A. J. P. C., Moreno, F. N., Piovan, S., Formigoni, M., Salgueiro-Pagadigorria, C. L., Godoi, V. A. F., Brito, M. N., and Garcia, R. F. 2018. "Goji Berry (Lycium barbarum) Extract Improves Biometric, Plasmatic and Hepatic Parameters of Rats Fed a High-Carbohydrate Diet." Journal of Pharmacy and Pharmacology 6. doi: 10.17265/2328-2150/2018-10.000

[24] Panchal, S. K., Poudyal, H., Iyer, A., Nazer, R., Alam, A., Diwan, V., Kauter, K., Sernia, C., Campbell, F., Ward, L., Gobe, G., Fenning, A., and Brown, L. 2011. "High-Carbohydrate High-Fat Diet-Induced Metabolic Syndrome and Cardiovascular Remodeling in Rats." $J$ Cardiovasc Pharmacol 57: 51-64.

[25] Grundy, S. M. 2016. "Metabolic Syndrome Update." Trends Cardiovasc Med 26: 364-73.

[26] Harms, P. G., and Ojeda, S. R. 1974. "A Rapid and Simple Procedure for Chronic Cannulation of the Rat Jugular vein.”J Appl Physiol 36 (3): 391-2. 
[27] Matthews, D. R., Hosker, J. P., Rudenski, A. S., Naylor, B. A., Treacher, D. F., and Turner, R. C. 1985. "Homeostasis Model Assessment: Insulin Resistance and $\beta$-Cell Function from Fasting Plasma Glucose and Insulin Concentrations in Man.” Diabetologia 28: 412-9.

[28] Campos, L. B., Gilglioni, E. H., Garcia, R. F., do Nascimento Brito, M., Natali, M. R. M., Ishii-Iwamoto, E. L., and Salgueiro-Pagadigorria, C. L. 2012. "Cimicifuga Racemosa Impairs Fatty Acid $\beta$-Oxidation and Induces Oxidative Stress in Livers of Ovariectomized Rats with Renovascular Hypertension." Free Radic Biol Medic 53: 680-9.

[29] Friedewald, W. T., Levy, R. I., and Fredrickson, D. S. 1972. "Estimation of the Concentration of Low-Density Lipoprotein Cholesterol in Plasma, without Use of the Preparative Ultracentrifuge." Clin Chem 18 (6): 499-502.

[30] Folch, J., Lees, M., and Sloane-Stanley, G. H. 1957. “A Simple Method for the Isolation and Purification of Total Lipids from Animal Tissues." J Biol Chem 226: 497-509.

[31] Rodbell M. 1964. "Metabolism of Isolated Fat Cells. Effects of Hormones on Glucose Metabolism and Lipolysis." J Biol Chem. 239: 357-80.

[32] Adams, L. A., and Ângulo, P. 2005. "Recent Concepts in Non-alcoholic Fatty Liver Disease." Diabet Med 22: 1129-33.

[33] Parrinello, C. M., and Selvin, E. 2014. "Beyond HbA1c and Glucose: The Role of Nontraditional Glycemic Markers in Diabetes Diagnosis, Prognosis, and Management." Curr Diab Rep 14: 548.

[34] Santosa, S., and Jensen, M. D. 2013. "Adipocyte Fatty Acid Storage Factors Enhance Subcutaneous Fat Storage in Postmenopausal Women." Diabetes 62: 775-82.

[35] Henegar, C., Tordjman, J., Achard, V., Lacasa, D., Cremer, I., Guerre-Millo, M., et al. 2008. "Adipose Tissue Transcriptomic Signature Highlights the Pathological Relevance of Extracellular Matrix in Human Obesity." Genome Biol 9. doi:10.1186/gb-2008-9-1-r14.

[36] Altomonte, J., Harbaran, S., Richter, A., and Dong, H. 2003. "Fat Depot-Specific Expression of Adiponectin Is Impaired in Zucker Fatty Rats.” Metabolism 52: 958-63.

[37] Harris, M., Hutchins, A., and Fryda, L. 2017. "The Impact of Virgin Coconut Oil and High-Oleic Safflower Oil on Body Composition, Lipids, and Inflammatory Markers in Postmenopausal Women." J Med Food 20: 345-51.

[38] Han, J., Hamilton, J. A., Kirkland, J. L., Corkey, B. E., and Guo, W. 2003. "Medium-Chain Oil Reduces Fat Mass and Down-Regulates Expression of Adipogenic Genes in Rats." Obes Res 11: 734-44.

[39] Zhu, L., Brown, W. C., Cai, Q., Krust, A., Chambon, P., McGuinness, O. P., and Stafford, J. M. 2013. "Estrogen Treatment after Ovariectomy Protects against Fatty Liver and May Improve Pathway-Selective Insulin Resistance." Diabetes 62: 424-34.

[40] Noland, R. C., Woodlief, T. L., Whitfield, B. R., Manning, S. M., Evans, J. R., Dudek, R. W., Lust, R. M., and Cortright, R. N. 2007. "Peroxisomal-Mitochondrial Oxidation in a Rodent Model of Obesity-Associated Insulin Resistance.” Am J Physiol Endocrinol Metab 293: E986-1001.

[41] Sparks, J. D., Sparks, C. E., and Adeli, K. 2012. "Selective Hepatic Insulin Resistance, VLDL Overproduction, and Hypertriglyceridemia." Arterioscler Thromb Vasc Biol 32: 2104-12.

[42] Robinson, D. S., Cryer, A., and Davies, P. 1975. "The Role of Clearing-Factor Lipase (Lipoprotein Lipase) in the Transport of Plasma Triglycerides." Proc Nutr Soc 34: 211-5.

[43] Bray, G. A., Lee, M., and Bray, T. L. 1980. "Weight Gain of Rats Fed Medium-Chain Triglycerides Is Less Than Rats Fed Long-Chain Triglycerides.” Int J Obes 4: 27-32.

[44] Hill, J. O., Peters, J. C., Yang, D., Sharp, T., Kaler, M., Abumrad, N. N., and Greene, H. L. 1989. "Thermogenesis in Humans during Overfeeding with Medium-Chain Triglycerides." Metabolism 38: 641-8.

[45] Turkenkopf, I. J., Maggio, C. A., and Greenwood, M. R. 1982. "Effect of High Fat Weanling Diets Containing Either Medium-Chain Triglycerides or Long-Chain Triglycerides on the Development of Obesity in the Zucker Rat." J Nutr 112: 1254-63.

[46] Prior, I. A., Davidson, F., Salmond, C. E., and Czochanska, Z. 1981. "Cholesterol, Coconuts, and Diet on Polynesian Atolls: A Natural Experiment: The Pukapuka and Tokelau Island Studies." Am J Clin Nutr 34: 1552-61.

[47] Lipoeto, N. I., Agus, Z., Oenzil, F., Wahlqvist, M., and Wattanapenpaiboon, N. 2004. "Dietary Intake and the Risk of Coronary Heart Disease among the Coconut-Consuming Minangkabau in West Sumatra, Indonesia." Asia Pac J Clin Nutr 13: 377-84.

[48] De Roos, N., Schouten, E., and Katan, M. 2001. "Consumption of a Solid Fat Rich in 1Auric Acid Results in a More Favorable Serum Lipid Profile in Healthy Men and Women Than Consumption of a Solid Fat Rich in Trans-Fatty Acids." J Nutr 131: 242-5.

[49] Gabbay, K. H., Hasty, K., Breslow, J. L., Ellison, R. C., Bunn, H. F., and Gallop, P. M. 1977. "Glycosylated Hemoglobins and Long-Term Blood Glucose Control in Diabetes Mellitus." J Clin Endocrinol Metab 44: 859-64.

[50] Bierhaus, A., Humpert, P. M., Morcos, M., Wendt, T., Chavakis, T., Arnold, B., Stern, D. M., and Nawroth, P. P. 2005. "Understanding RAGE, the Receptor for Advanced Glycation End Products." J Mol Med (Berl) 83: 876-86.

[51] Miyata, T., Hori, O., Zhang, J., Yan, S.D., Ferran, L., 
Rats Fed a High-Carbohydrate Diet

Lida, Y., and Schmidt, A. M. 1996. "The Receptor for Advanced Glycation End Products (RAGE) Is a Central Mediator of the Interaction of AGE-beta2 Microglobulin with Human Mononuclear Phagocytes via an Oxidant-Sensitive Pathway. Implications for the Pathogenesis of Dialysis-Related Amyloidosis." J Clin Invest 98: 1088-94.

[52] Inoguchi, T., Li, P., Umeda, F., Yu, H. Y., Kakimoto, M., Imamura, M., Aoki, T., Etoh, T., Hashimoto, T., Naruse, M., Sano, H., Utsumi, H., and Nawata, H. 2000. "High Glucose Level and Free Fatty Acid Stimulate Reactive
Oxygen Species Production through Protein Kinase C-Dependent Activation of $\mathrm{NAD}(\mathrm{P}) \mathrm{H}$ Oxidase in Cultured Vascular Cells.” Diabetes 49: 1939-45.

[53] Crompton, M., Virji, S., Doyle, V., Johnson, N., and Ward, J. M. 1999. "The Mitochondrial Permeability Transition Pore.” Biochem Soc Symp 66: 167-79.

[54] Aso, Y., Inukai, T., Tayama, K., and Takemura, Y. 2000. "Serum Concentrations of Advanced Glycation Endproducts Are Associated with the Development of Atherosclerosis as well as Diabetic Microangiopathy in Patients with Type 2 Diabetes.” Acta Diabetol 37: 87-92. 